\title{
Peters Plus syndrome: a recognizable clinical entity
}

\author{
Gizem Ürel Demir ${ }^{1}$, Naz Güleray Lafcr², Özlem Akgün Doğan¹, \\ Pelin Özlem Şimşek Kiper ${ }^{1}$, Gülen Eda Utine ${ }^{1}$ \\ ${ }^{1}$ Division of Pediatric Genetics, Department of Pediatrics and ${ }^{2}$ Department of Medical Genetics, Hacettepe University Faculty of \\ Medicine, Ankara, Turkey.
}

\begin{abstract}
Peters plus syndrome is a rare genetic condition wherein multiple systemic involvement with distinctive facial features are manifested, whilst the hallmark is Peters anomaly, occuring from anterior segment dysgenesis. Homozygous variants in the B3GLCT gene were identified to underlie this disorder. We here report on a onemonth-old female patient with typical features characteristic of Peters plus syndrome in whom a homozygous pathogenic mutation in the B3GLCT gene was detected.
\end{abstract}

Key words: Peters anomaly, Peters plus syndrome, B3GLCT.

Peters plus syndrome (PPS) (MIM 261540) is an autosomal recessive disorder characterized clinically by anterior chamber eye abnormalities and a constellation of multiple systemic defects. ${ }^{1,2}$ Developmental delay, limb shortening with brachydactyly, typical craniofacial features, and cleft palate/lip are among the other common findings. ${ }^{1,2}$ Although bilateral Peters anomaly is the most common ophtalmologic abnormality in PPS, unilateral involvement or a different anterior chamber defect may also be observed. ${ }^{1}$ Homozygous mutations in the B3GLCT (MIM 610308) on chromosome 13q12.3 have been described in the etiology in PPS. ${ }^{3} \mathrm{We}$ describe a one-month-old female patient with manifestations of PPS which was confirmed by B3GLCT sequencing analysis.

\section{Case Report}

A one-month-old female infant with dysmorphic features and disproportionate short stature was referred to our department for further evaluation. She was born at 39

Gizem Ürel Demir gizemurel@gmail.com

Received 11th September 2018; revised 3rd November 2018; accepted 22nd July 2019 weeks of gestation to first-cousin parents with a birthweight of $2320 \mathrm{~g}$ (-2.39 SD) and length of $43 \mathrm{~cm}(-3.01 \mathrm{SD})$ by cesarean section. The pregnancy was remarkable with the history of intrauterine growth retardation and short limbs which were detected after 28 weeks of gestation. Prenatal ultrasonography did not demonstrate any other abnormalities including eye findings or craniofacial pathologies. On admission, physical examination revealed a body length of $47 \mathrm{~cm}(-2.67 \mathrm{SD})$, a weight of $2,870 \mathrm{~g}(-2.16 \mathrm{SD})$ and a head circumference of $37 \mathrm{~cm}(-0.08 \mathrm{SD})$ compatible with growth retardation. Disproportionate shortening of the limbs with an arm span of $40 \mathrm{~cm}$ and brachydactyly was noted as well. She had a large anterior fontanelle with prominent forehead, widow's peak, hypertelorism, deep set eyes, broad and low nasal bridge with a bulbous tip, long philtrum, thin upper lip, and retromicrognathia. (Fig. 1). Peters anomaly was detected on eye examination performed due to corneal opacity, nystagmus and microphthalmia. Her metabolic screening was normal. Echocardiography revealed secundum atrial septal defect, peripheral pulmonary stenosis and trivial mitral valve regurgitation. Renal ultrasonography was unremarkable. Considering the distinctive findings of eye and disproportionate short stature, the patient was 


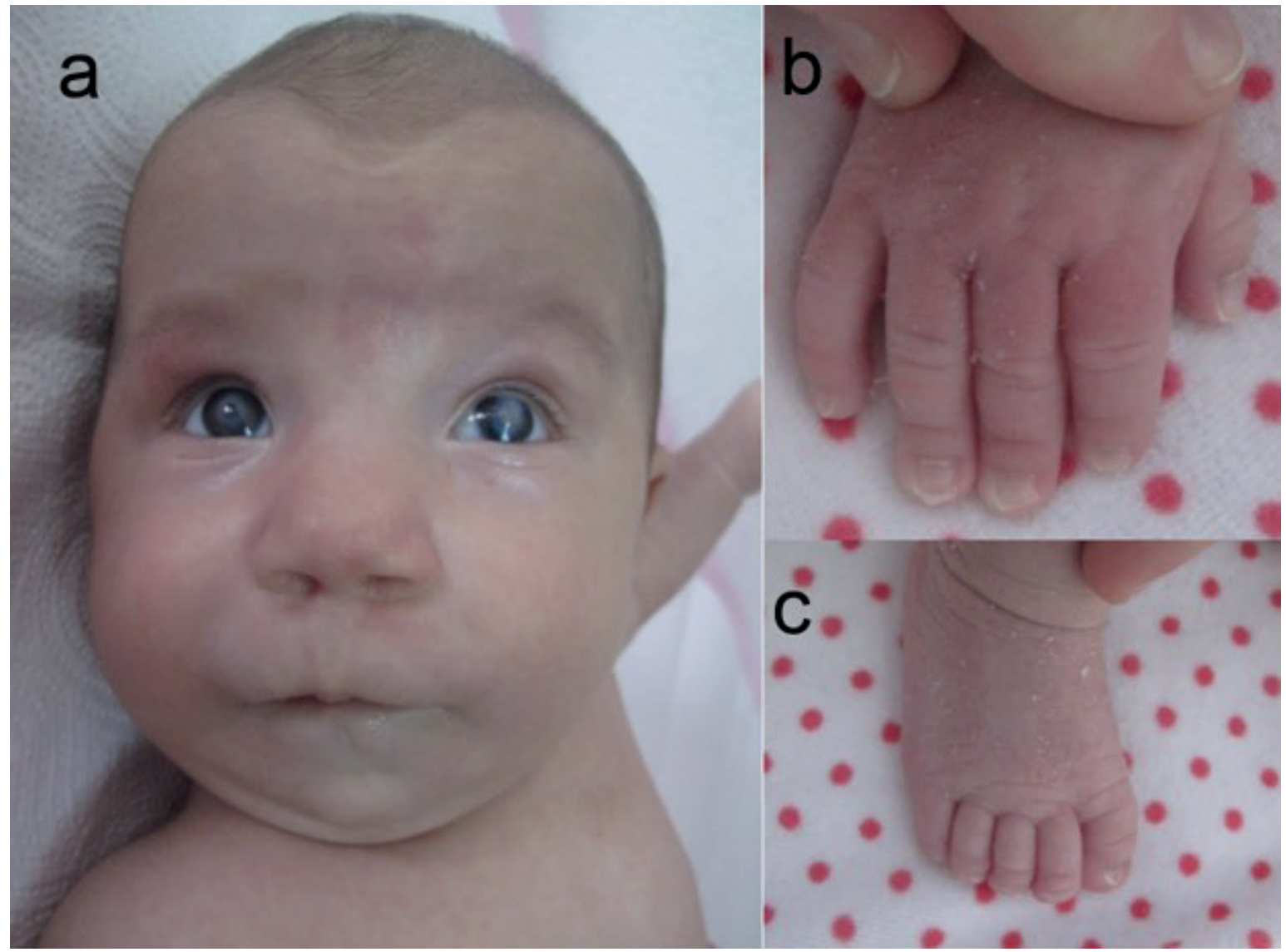

Fig. 1. Face (a), hand (b) and foot (c) appearance of the patient. Note bilateral corneal opacity, widow's peak, hypertelorism, low nasal bridge with a bulbous tip, long philtrum, thin upper lip, retromicrognathia (a), and brachydactyly $(b, c)$.

clinically diagnosed with PPS. After informed consent was taken from the family, peripheral blood samples were obtained from the patient and her parents. B3GLCT sequence analysis was performed and a pathogenic homozygous splice site mutation (c.660+1 G>A) was detected in the patient which was heterozygous in the parents confirming the autosomal recessive inheritance (Fig. 2).

The patient had bilateral corneal transplantation in order to improve visual acuity. Her evaluation at $2{ }^{5 / 12}$ years of age revealed body weight of $8500 \mathrm{~g}(-3.24 \mathrm{SD})$, height of $77 \mathrm{~cm}$ $(-3.90)$ and head circumference of $46.5 \mathrm{~cm}(-0.94$ SD). She achieved head and neck control at 6 months of age, sitting without support at 1 year of age, and walking at around 2 years of age. She was able to speak in sentences by 2 years of age. Denver developmental screening test was normal for her age.

Written informed consent to publish photographs was obtained from the family.

\section{Discussion}

In this clinical report, we have described a onemonth-old female patient with characteristic features of Peters plus syndrome in whom a homozygous pathogenic mutation in B3GLCT was detected.

PPS is an autosomal recessive condition defined by ocular anomalies, short limbs with broad distal extremities, typical facial features, and variable systemic abnormalities. ${ }^{1,2}$ In 1988, Saal et al. ${ }^{4}$ reported two sisters with anterior 
$\underline{a}$

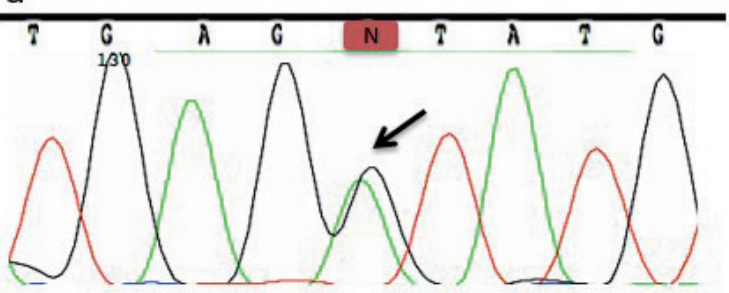

Het. c. $660+1 \mathrm{G}>\mathrm{A}$

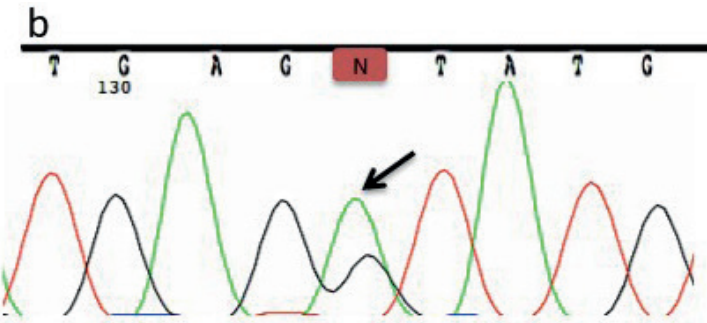

Het. c. $660+1 \mathrm{G}>\mathrm{A}$

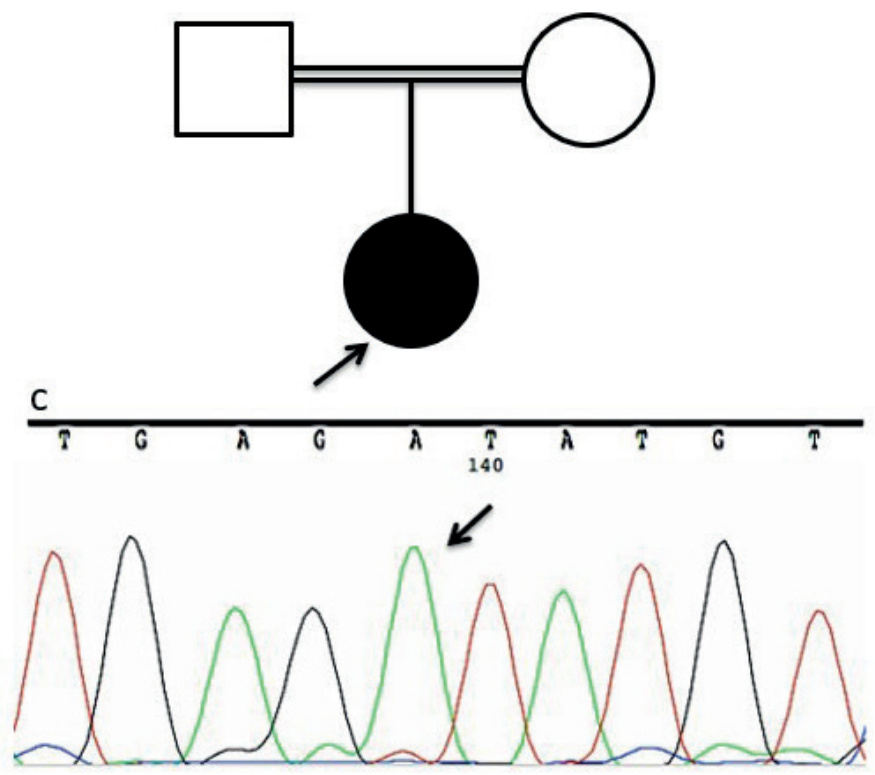

Hom. c. $660+1 \mathrm{G}>\mathrm{A}$

Fig. 2. Sequence analysis of the B3GLCT gene in the patient (homozygous) (c) and the parents (heterozygous) $(\mathrm{a}, \mathrm{b})$ shows a splice site mutation (c.660+1 G>A).

chamber anomalies of consanguineous parents suggesting autosomal recessive inheritance despite of resembling Robinow syndrome with the other associated features. Subsequently, Van Schooneveld et al. ${ }^{5}$, in 1984, described 11 patients with similar phenotype and termed the entity as Peters plus syndrome (PPS).

Peters anomaly is the most common anterior chamber defect of the eye in PPS. ${ }^{6-8}$ The most obvious feature of the Peters anomaly, which is a severe congenital anterior segment dysgenesis, is corneal opacity. This finding may be accompanied by various eye anomalies such as thinning or absence of corneal endothelium and Descemet's membrane, iridocorneal adhesions, and occasionally microphthalmia and cataracts. ${ }^{6-8}$ Glaucoma is present in half of the patients at birth, and exacerbates the visual impairment. ${ }^{1,9}$ Bilateral Peters anomaly was detected in the present patient as aforementioned and she had bilateral corneal transplantation whithin the first month of life in order to improve visual acuity and she is still under follow-up in terms of glaucoma.

Typical facial features of PPS include round face, a prominent forehead, hypertelorism, long philtrum, micrognathia, ear anomalies, Cupid's bow shaped upper lips, a thin vermillion border and a broad neck. ${ }^{1}$ Rhizomelic shortening with broad hands and brachydactyly are the constant components of the syndrome while, other skeletal findings including thorax deformities, kyphoscoliosis, vertebral segmentation defects, short metatarsal and metacarpal bones, 
clinodactyly of the fifth finger, syndactyly, and pes cavus can also be observed.1,2,10 Growth retardation is prenatal onset and good response to growth hormone replacement therapy has been reported previously. ${ }^{1,11}$ Growth retardation along with the facial and skeletal findings of the present patient were quite suggestive of PPS.

Individuals with PPS exhibit varying degrees of intellectual disability with or without structural brain abnormalities and epilepsy., ${ }^{1,212,13}$ Microcephaly, macrocephaly, cleft palate/lip, and conductive hearing loss have also been reported among the other manifestations, however, these findings were all absent in our patient. ${ }^{1,2,13,14}$ Defects affecting the central nervous system, including hydrocephaly, agenesis of the corpus callosum, and neural tube defects have also been described.6,12,13,15,16 Congenital heart defects including atrial septal defect, ventricular septal defect, aortic stenosis, pulmonary stenosis, bicuspid pulmonary valve, hypoplastic left heart, absence of right pulmonary artery and vein have been reported as associated with PPS. ${ }^{1,2,4,16,17}$ In this case, atrial septal defect and peripheral pulmonary stenosis were detected. Abnormalities involving the genitourinary system include hydronephrosis, vesicoureteral reflux, ectopic kidney, renal agenesis, renal and ureteral duplication, renal hypoplasia, oligomeganephronia, multicystic dysplastic kidney, and glomerulocystic kidneys, which were not present in our patient. ${ }^{6,14,16}$

Prenatal diagnosis of PPS is possible, however, it remains difficult due to nonspesific findings and limitations of ultrasound imaging. The prenatal ultrasound features defined in association with the syndrome are microcephalia, ventriculomegaly, agenesis of corpus callosum, microphthalmia, hyperechogenicity of the anterior chamber, cleft lip/palate, shortening of long bones, multicystic kidney, and dysmorphic facial characteristics of PPS. ${ }^{18,19}$ PPS should be kept in mind in a fetus with typical ocular abnormalities, unusual facial appearance and shortness of long tubular bones, especially in the presence of a positive family history. In such instances, prenatal diagnosis might be an option for the couples. In the present case growth retardation and short limbs were detected prenatally, however, evidence was insufficient to establish the diagnosis of PPS because of the absence of the finding of scrutiny of eyes.

Based on all clinical findings, including anterior chamber defect of the eye, short stature with short limbs, and prominent facial features, PPS was suspected and the diagnosis was confirmed by molecular analysis of B3GLCT. B3GLCT, previously called B3GALTL, which is located on chromosome 13q12.3 was identified as the causative gene for PPS by Lesnik Oberstein et $\mathrm{al}^{3}{ }^{3}$ in 2006. B3GLCT encodes a $\beta 1,3-$ glucosyltransferase which is involved in the glycosylation and functions by adding glucose to O-fucose attached to thrombospondin type 1 repeats (TSRs) by protein O-fucosyltransferase 2 (POFUT2) ${ }^{20}$ Loss-of-function mutations in the B3GLCT cause degradation of glycosylation. ${ }^{21}$ The splice site mutation in intron 8 [c.660+1G>A] is the most common mutation reported and also is present in our patient. ${ }^{21}$ Unlike the other defects of enzymes that are involved in proteoglycan biosynthesis, B3GLCT defects are not related to joint dislocations, radioulnar synostosis, and generalized osteopenia. Peters anomaly, short stature and brachydactyly constitute the mandatory triad that is essential for the recognition of classic PPS.

In conclusion, patients with anterior chamber defects of the eye, particularly Peters anomaly, and other common systemic manifestations should prompt consideration of PPS. B3GLCT sequence analysis should be undertaken in order to confirm the clinical diagnosis for providing appropriate genetic counseling and options of prenatal diagnosis.

\section{REFERENCES}

1. Maillette de Buy Wenniger-Prick LJJM, Hennekam RCM. The Peters' plus syndrome: a review. Ann Genet 2002; 45: 97-103.

2. Hennekam RC, Van Schooneveld MJ, Ardinger $\mathrm{HH}$, et al. The Peters'-Plus syndrome: description of 16 patients and review of the literature. Clin Dysmorphol 1993; 2: 283-300. 
3. Lesnik Oberstein SAJ, Kriek M, White SJ, et al. Peters Plus syndrome is caused by mutations in B3GALTL, a putative glycosyltransferase. Am J Hum Genet 2006; 79: 562-566.

4. Saal HM, Greenstein RM, Weinbaum PJ, Poole AE. Autosomal recessive Robinow-like syndrome with anterior chamber cleavage anomalies. Am J Med Genet 1988; 30: 709-718.

5. Van Schooneveld MJ, Delleman JW, Beemer FA, Bleeker-Wagemakerp EM. Peters'-plus: a new syndrome. Ophthalmic Paediatr Genet 1984; 4: 141145.

6. Motoyama O, Arai H, Harada R, Hasegawa K, Iitaka K. A girl with Peters plus syndrome associated with myelomeningocele and chronic renal failure. Clin Exp Nephrol 2010; 14: 381-384.

7. Heon E, Barsoum-Homsy M, Cevrette L, et al. Peters' anomaly. The spectrum of associated ocular and systemic malformations. Ophthalmic Paediatr Genet 1992; 13: 137-143.

8. Peters A. Uber angeborene Defektbildung des Descemet' schen Membran. Klin Mbl Augenheilk 1906; 44: 27-40.

9. Traboulsi EI, Maumenee IH. Peters' anomaly and associated congenital malformations. Arch Ophthalmol 1992; 110: 1739-1742.

10. Kapoor S, Mukherjee SB, Arora R, Shroff D. Peters plus syndrome. Indian J Pediatr 2008; 75: 635-637.

11. Lee KW, Lee PDK. Growth hormone deficiency (GHD): a new association in Peters' Plus syndrome (PPS). Am J Med Genet A 2004; 124A: 388-391.

12. Camera G, Centa A, Pozzolo S, Camera A. Peters' plus syndrome with agenesis of the corpus callosum: report of a case and confirmation of autosomal recessive inheritance. Clin Dysmorphol 1993; 2: 317321.
13. Schoner K, Kohlhase J, Müller AM, et al. Hydrocephalus, agenesis of the corpus callosum, and cleft lip/palate represent frequent associations in fetuses with Peters' plus syndrome and B3GALTL mutations. Fetal PPS phenotypes, expanded by Dandy-Walker cyst and encephalocele. Prenat Diagn 2013; 33: 75-80.

14. Lesnik Oberstein SAJ, Ruivenkamp CAL, Hennekam RC. Peters plus syndrome. In: Adam MP, Ardinger $\mathrm{HH}$, Pagon RA et al (eds): Gene Reviews (Internet). Seattle, WA, USA: University of Washington, Seattle, 2007 (updated 24 Aug 2017).

15. Cabral de Almeida JC, Reis DF, Llerena J, et al. Short stature, brachydactyly, and Peters' anomaly (Peters'-plus syndrome): confirmation of autosomal recessive inheritance. J Med Genet 1991; 28: 277-279.

16. Lacombe D, Llanas B, Chateil JF, Sarrazini E, Carles D, Battin J. Severe presentation of Peters' Plus syndrome. Clin Dysmorphol 1994; 3: 358-360.

17. Shimizu R, Saito R, Hoshino K, et al. Severe Peters Plus syndrome-like phenotype with anterior eye staphyloma and hypoplastic left heart syndrome: proposal of a new syndrome. Congenit Anom (Kyoto) 2010; 50: 197-199.

18. Gupta N, Kaul A, Kabra M. Prenatal diagnosis of fetal Peters' Plus syndrome: a case report. Case Rep Genet 2013; 2013: doi: /10.1155/2013/364529.

19. Boog G, Le Vaillant C, Joubert M. Prenatal sonographic findings in Peters-plus syndrome. Ultrasound Obstet Gynecol 2005; 25: 602-606.

20. Weh E, Takeuchi H, Muheisen S, Haltiwanger RS, Semina EV. Functional characterization of zebrafish orthologs of the human Beta 3-Glucosyltransferase B3GLCT gene mutated in Peters Plus syndrome. PLoS One 2017; 12: e0184903.

21. Reis LM, Tyler RC, Abdul-Rahman O, et al. Mutation analysis of B3GALTL in Peters Plus syndrome. Am J Med Genet A 2008; 146A: 2603-2610. 